TITLE:

\title{
Nondestructive high-resolution solid-state NMR of rotating thin films at the magic-angle.
}

\section{AUTHOR(S):}

Inukai, Munehiro; Noda, Yasuto; Takeda, Kazuyuki

\section{CITATION:}

Inukai, Munehiro ... [et al]. Nondestructive high-resolution solid-state NMR of rotating thin films at the magic-angle.. Journal of magnetic resonance 2011, 213(1): 192-195

\section{ISSUE DATE:}

2011-12

URL:

http://hdl.handle.net/2433/150443

\section{RIGHT:}

@ 2011 Elsevier Inc.; この論文は出版社版でありません。引用の際には 出版社版をご確認ご利用ください。; This is not the published version. Please cite only the published version. 


\title{
Nondestructive high-resolution solid-state NMR of rotating thin films at the magic-angle
}

Munehiro Inukai $^{\text {a*}}$, Yasuto Noda ${ }^{a}$, Kazuyuki Takeda ${ }^{a}$

a Department of Chemistry, Graduate School of Science, Kyoto University, Kitashirakawa Oiwake-cho, Sakyo-ku, Kyoto 606-8502, Japan.

\begin{abstract}
We present a new approach to nondestructive magic-angle spinning (MAS) nuclear magnetic resonance (NMR) for thin films. In this scheme, the sample put on the top of a rotor is spun using the conventional MAS system, and the NMR signals are detected with an additional coil. Stable spinning of disk-shaped samples with diameters of $7 \mathrm{~mm}$ and $12 \mathrm{~mm}$ at 14.2 and $7 \mathrm{kHz}$ are feasible. We present ${ }^{7} \mathrm{Li}$ MAS NMR experiments of a thin-film sample of $\mathrm{LiCoO}_{2}$ with a thickness of $200 \mathrm{~nm}$. Taking advantage of the nondestructive feature of the experiment, we also demonstrate ex-situ experiments, by tracing conformation change upon annealing for various durations. This approach opens the door for in-situ MAS NMR of thin-film devices as well.
\end{abstract}

*Corresponding Author:

Munehrio Inukai, Ph.D.

\section{Present address}

Institute for Integrated Cell-Material Sciences

Kyoto University

Yoshida, Sakyo-ku, Kyoto 606-8501, Japan.

Tel: 075-383-2735

Fax: 075-383-2732

E-mail: minukai@icems.kyoto-u.ac.jp 


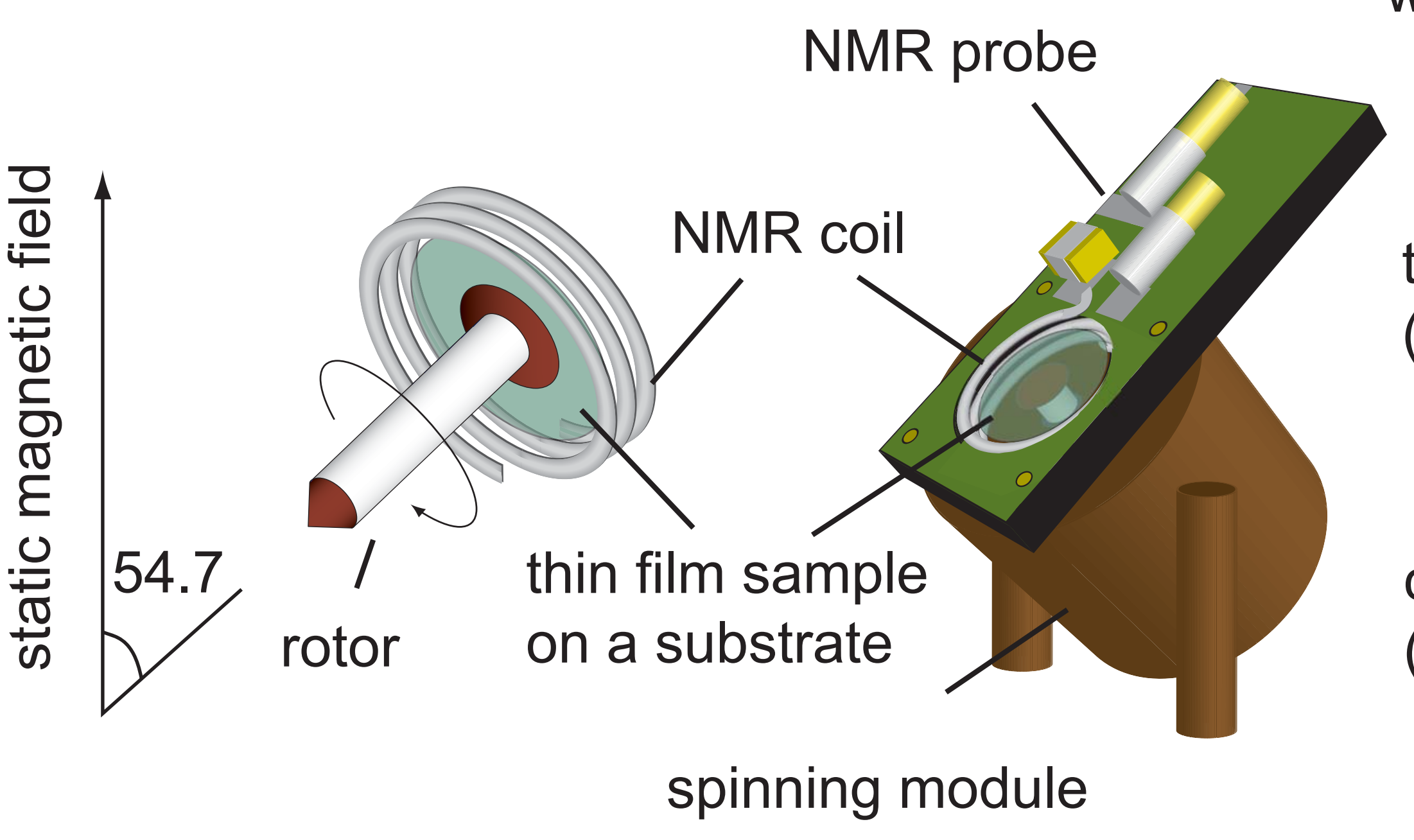

NMR spectra of $\mathrm{LiCoO}_{2}$ thin film with thickness of $200 \mathrm{~nm}$

spinning modul conventional method

this work

(spinning at $5 \mathrm{kHz}$ )

(static)

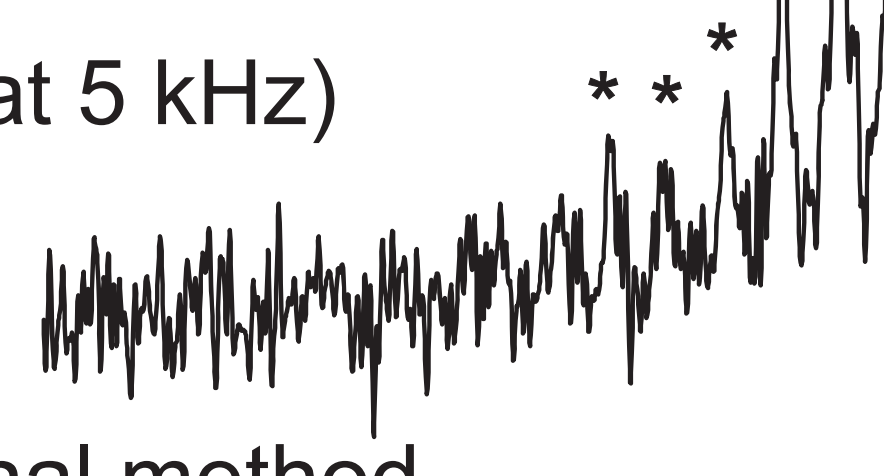

My

$\begin{array}{cccccc}600 & 400 \quad 200 & 0 & -200 & -400 & -600 \\ & 7 \text { Li chemical Shift / ppm }\end{array}$


Thin-film devices show a wide variety of functions, depending on their conformation, thickness, and layer composition. For their characterization, various analytical methods have been used. Among them, solid-state nuclear magnetic resonance (SSNMR) has the following unique features. First, materials in an amorphous phase can be analyzed as well as in a crystalline phase, in contrast to the diffraction means. Second, the spectrum reflects the local magnetic environments, whence information as to the electron states can be extracted. Despite that SSNMR can complement characterization by the other methods, it has not been widely used in the studies of the thin-film devices so far.

One of the reasons is that the conventional SSNMR with magic angle spinning (MAS)[1, 2], which is an essential technique providing high-resolution spectra for polycrystalline samples by mechanical sample rotation around an axis tilted at the magic angle $\left(54.7^{\circ}\right)$ to the external magnetic field, employs a rotor optimized for powder samples. A few MAS NMR works on the thin-film samples reported so far resorted to either scratching the sample off the substrate before being packed into the rotor[3-7], or stacking many small pieces of the films that fit in the rotor[8-10]. These approaches require tedious sample preparation. Furthermore, the experiments destroy the sample, hampering ex-situ characterization of the thin-film devices. So far, nondestructive SSNMR analyses of the thin films have only been feasible in non-spinning samples[11], in which high-resolution measurement is limited to samples without anisotropic structure.

Here, we present a new approach to nondestructive MAS NMR of thin films, named as disk MAS. Fig. 1(a) illustrates the strategy, in which the film sample made on a disk-shaped substrate is put on the top of the rotor, and spun together with the rotor. As compared to MAS of a thin capillary tube put on the top of the rotor[12-14], spinning of a flat body requires even more careful adjustment of the mechanical balance, as the moment of inertia for the disk is much larger than that for the capillary. Using a jig, we glued a circular quartz substrate to an attachment at the exact coaxial position, which was then mounted on the top of a Varian $4 \mathrm{~mm}$ rotor, as shown in Fig. 1(b). We verified stable spinning at 7 and $14.2 \mathrm{kHz}$ for sample diameters of 12 and $7 \mathrm{~mm}$ respectively, whereas the nominal maximum spinning speed for the unmodified system was $15.0 \mathrm{kHz}$. Furthermore, we found that even a square quartz substrate with a length of $8 \mathrm{~mm}$ (Fig.1(c)) was stably spun at $7 \mathrm{kHz}$, by positioning its center of mass on the spinning axis precisely. 
In order to apply radiofrequency (RF) pulses to the thin-film sample and detect NMR signals, an additional probe was employed, as described in Fig. 1(a). Fig. 2(a) shows a balanced resonant circuit composed of the coil, chip capacitors (American Technical Ceramics Corp.), and trimmer capacitors (Voltronics Corp.). The coil and the capacitors were assembled into a compact board and attached to the spinning module, as shown in Fig. 2(b). The coil was wound with a silver wire. Its diameter, length, and number of turns were $14 \mathrm{~mm}, 5 \mathrm{~mm}$, and 3, respectively. The circuit was tuned at $116.4 \mathrm{MHz}$, which corresponds to the ${ }^{7} \mathrm{Li}$ Larmor frequency in a magnetic field of $7 \mathrm{~T}$. The quality factor was measured to be 150 .

To calibrate the RF amplitude and RF inhomogeneity, we carried out ${ }^{7} \mathrm{Li}$ nutation experiments using $1 \mathrm{M} \mathrm{LiCl}$ aqueous solution. The liquid sample put in a cylindrical container with a diameter of $12 \mathrm{~mm}$ and a depth of $400 \mu \mathrm{m}$ was placed at the position where the disk sample was to be located. The container was made with a cylindrical PTFE rod. Using a lathe, a pit with a depth of $400 \mu \mathrm{m}$ was made on the rod. Then, the pit was sealed with a cover glass, and the liquid reference sample was injected. $\mathrm{KBr}$ powder was packed into the rotor, so as to adjust the magic angle through measurement of the rotational echoes of the ${ }^{79} \mathrm{Br}$ FID using the coil of the MAS probe. Even though the thin film was axially off the magnet center, magnetic field homogeneity of less than 1 ppm was attained by the conventional shimming.

Fig. 2(c) shows power dependence of the RF amplitude for the disk MAS probe. For comparison, the result obtained using a home-built $4 \mathrm{~mm}$ MAS probe, whose quality factor was measured to be 41 , is also plotted. We verified that the RF efficiency of the disk MAS probe was lower than that of the MAS probe only by a factor of 2.0. This is ascribed to the higher quality factor of the disk MAS probe. From the decay of the nutation curve, the RF inhomogeneity was estimated to be ca. $16 \%$ over the sample volume.

For comparison of spectral resolution between the static and the disk MAS experiments, we carried out single-pulse ${ }^{7} \mathrm{Li}$ SSNMR measurements of a thin layer of $\mathrm{LiCoO}_{2}$, which is widely used for a cathode material of thin-film lithium ion batteries[15]. A $\mathrm{LiCoO}_{2}$ thin film with a thickness of $200 \mathrm{~nm}$ was sputtered at room temperature on a quartz substrate with a diameter of $12 \mathrm{~mm}$. The sample volume and the number of the ${ }^{7} \mathrm{Li}$ spins were estimated to be $22.6 \mathrm{~nL}$ and $1.1 \mu \mathrm{mol}$. Then, the sample was annealed in a furnace at $600{ }^{\circ} \mathrm{C}$ for 30 minutes. The ${ }^{7} \mathrm{Li}$ FID was accumulated over 
300000 times with relaxation delay of $100 \mathrm{~ms}$ in $7 \mathrm{~T}$. The experimental time was 8.5 hours. The pulse width was $8 \mu$ s with an input power of $54 \mathrm{~W}$, and the RF amplitude was $25 \mathrm{kHz}$.

Fig. 3 shows ${ }^{7} \mathrm{Li}$ SSNMR spectra of the $\mathrm{LiCoO}_{2}$ thin film under static condition (a) and disk MAS at $5 \mathrm{kHz}$ (b). While no appreciable signals were observed without sample spinning, disk MAS revealed a center peak at $0 \mathrm{ppm}$ and a number of spinning sidebands. Considering the similar profile of the spinning side-bands reported in ${ }^{7} \mathrm{Li}$ MAS NMR of $\mathrm{LiCoO}_{2}$ in the paramagnetic state[16-18], a part of the diamagnetic $\mathrm{Co}^{3+}$ ions in the $\mathrm{LiCoO}_{2}$ thin film have presumably changed into paramagnetic $\mathrm{Co}^{2+}$ ions. In the disk MAS spectrum, the dipolar couplings between the ${ }^{7} \mathrm{Li}$ spins and the $\mathrm{Co}^{2+}$ ions were partially averaged by sample spinning, while in the static spectrum the resonance line was broadened and obscured.

For comparison of signal-to-noise ratio (SNR), we also carried out ${ }^{7} \mathrm{Li}$ MAS NMR measurements using the $4 \mathrm{~mm}$ probe. After the disk MAS measurement shown in Fig. 3(b), the thin film was crushed together with the quartz substrate. The amount of the powder that could be located in the coil was ca. 40 percent of that of the original sample. The ${ }^{7} \mathrm{Li}$ spectrum obtained under the same experimental conditions is shown in Fig. 3(c). We found no discernible change in the spectrum. In disk MAS, the SNR (25) was higher compared to the case of the conventional MAS (16). Considering the sample volume put in the coil, the result is consistent with the RF efficiencies because the SNR of the 4 $\mathrm{mm}$ rotor should be multiplied by ca. 2.5 .

An important feature of disk MAS is that a flat sample can be nondestructively put off the attachment. This enables us to characterize the identical thin-film device undergoing various processes like annealing, discharging/charging for crystallization and degradation, and so on. In order to demonstrate the possibility of such ex-situ experiments of the thin films, disk MAS NMR measurement and sample annealing were repeated using a single thin-film sample of $\mathrm{LiCoO}_{2}$. First, a ${ }^{7} \mathrm{Li}$ disk MAS spectrum of a thin-film $\mathrm{LiCoO}_{2}$ with a thickness of $200 \mathrm{~nm}$ was obtained in the above experimental condition. After the NMR measurement, the sample was removed from the attachment, annealed at $400{ }^{\circ} \mathrm{C}$ for 3 minutes in a pre-warmed furnace, and cooled in the atmosphere. Then the sample was mounted on the attachment again, and disk MAS NMR was performed in the same experimental condition. The above experimental steps were repeated until the total annealing time was 18 minutes. 
Fig. 4 shows ex-situ ${ }^{7} \mathrm{Li}$ disk MAS NMR spectra. The spectrum of non-annealed (as-deposited) sample showed relatively weak signals. The intensity of the center peak after the first annealing time of 3 minutes increased by a factor 7.7. Then the intensity gradually grew as further annealing the sample for up to 18 minutes, as shown in Fig. 5. In a recent report, a $\mathrm{LiCoO}_{2}$ thin film sputtered at room temperature was found to be mostly amorphous, and crystallizes after annealing for 9-15 minutes[19]. The change in the spectra observed in the present work suggests that the as-deposited $\mathrm{LiCoO}_{2}$ thin film in the amorphous phase underwent transition into the crystalline phase within 3 minutes.

In summary, we have developed a new approach to nondestructive MAS NMR of thin films, and have demonstrated the ex-situ MAS NMR experiments in sputtered $\mathrm{LiCoO}_{2}$. The annealing process of this sample has successfully been traced. Considering that most atomic elements possess NMR-active nuclei, disk MAS can be used for versatile NMR analysis of the thin-film samples. Toward its practical use, there is still room for improvement, such as optimization of coil geometry, development of doubly-tuned disk MAS probe, and further increase in spinning frequency. In addition, disk MAS potentially provides in-situ MAS NMR experiments with operations from the exposed side. Examples of such include laser irradiation, laser heating, microwave irradiation, and gas blowing. When further progress is made, disk MAS could push the NMR studies of various thin-film devices forward.

\section{Acknowledgment}

We are grateful to Prof. K. Takegoshi (Kyoto University) for fruitful discussions. This work was financially supported by Core Research of Evolutional Science and Technology of Japan Science and Technology agency (CREST/JST) 


\section{References}

[1] E.R. Andrew, A. Bradbury, R.G. Eades, Nuclear magnetic resonance spectra from a crystal rotated at high speed, Nature 182 (1958) 1659-1659.

[2] E.R. Andrew, A. Bradbury, R.G. Eades, Removal of dipolar broadening of nuclear magnetic resonance spectra of solids by specimen rotation, Nature 183 (1959) 1802-1803.

[3] T.M. Alam, H.Y. Fan, Investigation of templated mesoporous silicate thin films using high speed, solid-state H-1 MAS and double quantum NMR Spectroscopy, Macromol. Chem. Phys. 204 (2003) 2023-2030.

[4] K. Landskron, B.D. Hatton, D.D. Perovic, G.A. Ozin, Periodic mesoporous organosilicas containing interconnected $\left[\mathrm{Si}\left(\mathrm{CH}_{2}\right)\right]_{3}$ rings, Science 302 (2003) 266-269.

[5] B.D. Hatton, K. Landskron, W. Whitnall, D.D. Perovic, G.A. Ozin, Spin-coated periodic mesoporous organosilica thin films - Towards a new generation of low-dielectric-constant materials, Adv. Funct. Mater. 15 (2005) 823-829.

[6] A. Mazaj, S. Costacurta, N.Z. Logar, G. Mali, N.N. Tusar, P. Innocenzi, L. Malfatti, F. Thibault-Starzyk, H. Amenitsch, V. Kaucic, G. Soler-Illia, Mesoporous aluminophosphate thin films with cubic pore arrangement, Langmuir 24 (2008) 6220-6225.

[7] C.A. Steinbeck, M. Ernst, B.H. Meier, B.F. Chmelka, Anisotropic optical properties and structures of block copolymer/silica thin films containing aligned porphyrin J-aggregates, J. Phys. Chem. C 112 (2008) 2565-2573.

[8] C. Glaubitz, A. Watts, Magic angle-oriented sample spinning (MAOSS): A new approach toward biomembrane studies, J. Magn. Reson. 130 (1998) 305-316.

[9] N.A. Oyler, R. Tycko, Absolute structural constraints on amyloid fibrils from solid-state NMR spectroscopy of partially oriented samples, J. Am. Chem. Soc. 126 (2004) 4478-4479.

[10] D.L. VanderHart, V.M. Prabhu, K.A. Lavery, C.L. Dennis, A.B. Rao, E.K. Lin, Thin-film solid-state proton NMR measurements using a synthetic mica substrate: Polymer blends, J. Magn. Reson. 201 (2009) 100-110.

[11] J.P. Yesinowski, Ga-69,Ga-71 and N-14 high-field NMR of gallium nitride films, in: M. Stutzmann (Ed.), Phys. Stat. Sol. C 7 (2005) 2399-2402.

[12] H. Janssen, A. Brinkmann, E.R.H. van Eck, P.J.M. van Bentum, A.P.M. Kentgens, Microcoil high-resolution magic angle spinning NMR spectroscopy, J. Am. Chem. Soc. 128 (2006) 8722-8723.

[13] K. Yamauchi, T. Asakura, Development of microMAS NMR probehead for 
mass-limited solid-state samples, Chem. Lett. 35 (2006) 426-427.

[14] M. Inukai, K. Takeda, Studies on multiple-quantum magic-angle-spinning NMR of half-integer quadrupolar nuclei under strong rf pulses with a microcoil, Concepts Magn. Reson. B 33 (2008) 115-123.

[15] J.B. Bates, N.J. Dudney, B. Neudecker, A. Ueda, C.D. Evans, Thin-film lithium and lithium-ion batteries, Solid State Ionics 135 (2000) 33-45.

[16] M. Menetrier, Y. Shao-Horn, A. Wattiaux, L. Fournes, C. Delmas, Iron substitution in lithium-overstoichiometric " $\mathrm{Li}_{1.1} \mathrm{CoO}_{2}$ ": Combined Fe-57 Mossbauer and Li-7 NMR spectroscopies studies, Chem. Mater. 17 (2005) 4653-4659.

[17] K. Nakamura, H. Hirano, D. Nishioka, S. Endou, K. Itsuki, Y. Michihiro, T. Moriga, N. Kuwata, J. Kawamura, Ionic diffusion and structural changes in lithium compounds, Solid State Ionics 180 (2009) 621-625.

[18] M.P.J. Peeters, M.J. van Bommel, P. Wolde, H.A.M. van Hal, W.C. Keur, A.P.M. Kentgens, A Li-6, Li-7 and Co-59 MAS NMR study of rock salt type $\mathrm{Li}_{\mathrm{x}} \mathrm{CoO}_{2}(0.48<=$ $\mathrm{x}<=1.05$ ), Solid State Ionics 112 (1998) 41-52.

[19] H.Y. Park, S.C. Nam, Y.C. Lim, K.G. Choi, K.C. Lee, G.B. Park, J.B. Kim, H.P. Kim, S.B. Cho, $\mathrm{LiCoO}_{2}$ thin tilm cathode fabrication by rapid thermal annealing for micro power sources, Electrochim. Acta 52 (2007) 2062-2067. 


\section{Figure caption}

Fig. 1. (a) A schematic description of disk MAS. (b) A photograph of a $4 \mathrm{~mm}$ pencil type rotor (Agilent technology, Inc.) with an attachment and a quartz disk substrate with a diameter of $12 \mathrm{~mm}$. (c) A photograph of a $8^{\times} 8 \mathrm{~mm}$ square quartz substrate.

Fig. 2. (a) An electric circuit tuned at $116.4 \mathrm{MHz}$ in a disk MAS probe. The inductance $\mathrm{L}_{\mathrm{S}}$ of sample coil, capacitances $\mathrm{C}_{1}, \mathrm{C}_{2}$, and $\mathrm{C}_{3}$ were $120 \mathrm{nH}, 1-25 \mathrm{pF}, 1-25 \mathrm{pF}, 30 \mathrm{pF}$, respectively. $\mathrm{C}_{3}$ serves for balancing. (b) The disk MAS probe. A solenoid coil, two variable capacitors, and a capacitor were assembled on an acrylic plate. (c) Power dependence of the RF amplitude in the disk MAS probe (filled cycles) and a home-built $4 \mathrm{~mm}$ MAS probe using a Varian spinning module (open circles). The RF amplitude was obtained from the ${ }^{7} \mathrm{Li}$ nutation experiment in $\mathrm{LiCl}$ aqueous solution. The data points were fitted by a square root function of the form $y=a \sqrt{x}$, and the coefficient $a$ is depicted for each set of the data.

Fig. 3. ${ }^{7} \mathrm{Li}$ NMR spectra of a $\mathrm{LiCoO}_{2}$ thin film with a thickness of $200 \mathrm{~nm}$ annealed at $600{ }^{\circ} \mathrm{C}$ for 30 minutes under static condition (a) and disk MAS at $5 \mathrm{kHz}$ (b). For comparison of signal-to-noise ratio, a ${ }^{7} \mathrm{Li}$ NMR spectrum of the crushed $\mathrm{LiCoO}_{2}$ thin film was also obtained with the home-built $4 \mathrm{~mm}$ MAS probe (c). The carrier frequency and the spinning speed were $116.4 \mathrm{MHz}$ and $5 \mathrm{kHz}$. The peaks denoted with the asterisks are the spinning sidebands.

Fig. 4. Ex-situ ${ }^{7} \mathrm{Li}$ disk MAS NMR spectra of an identical $\mathrm{LiCoO}_{2}$ thin film repeatedly annealed at $400{ }^{\circ} \mathrm{C}$ with an interval time of 3 minutes. The experimental conditions were the same as those in Fig. 3.

Fig. 5. Annealing time dependence of the intensities of the center peak of ${ }^{7}$ Li disk MAS spectra in the $\mathrm{LiCoO}_{2}$ thin-film sample. 


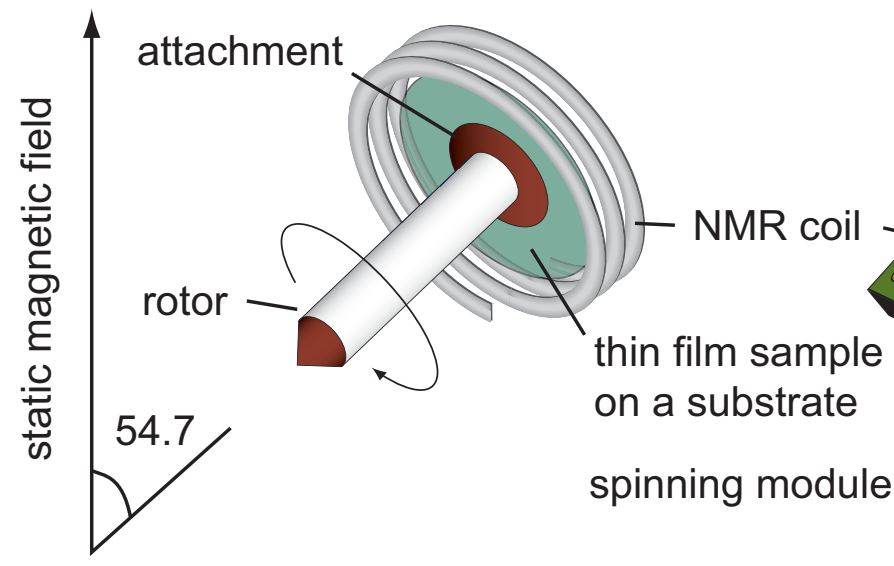

NMR probe

(b)

\section{front view}

(c)

side view

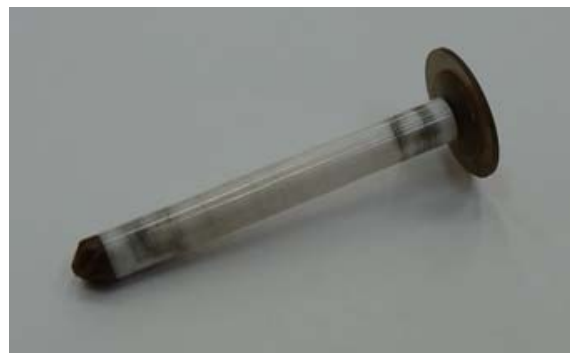

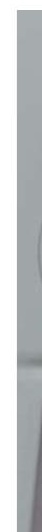

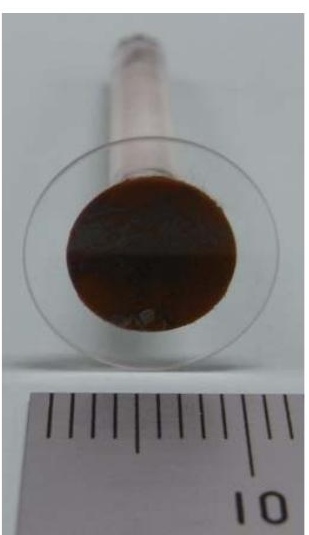

Fig. 1. 

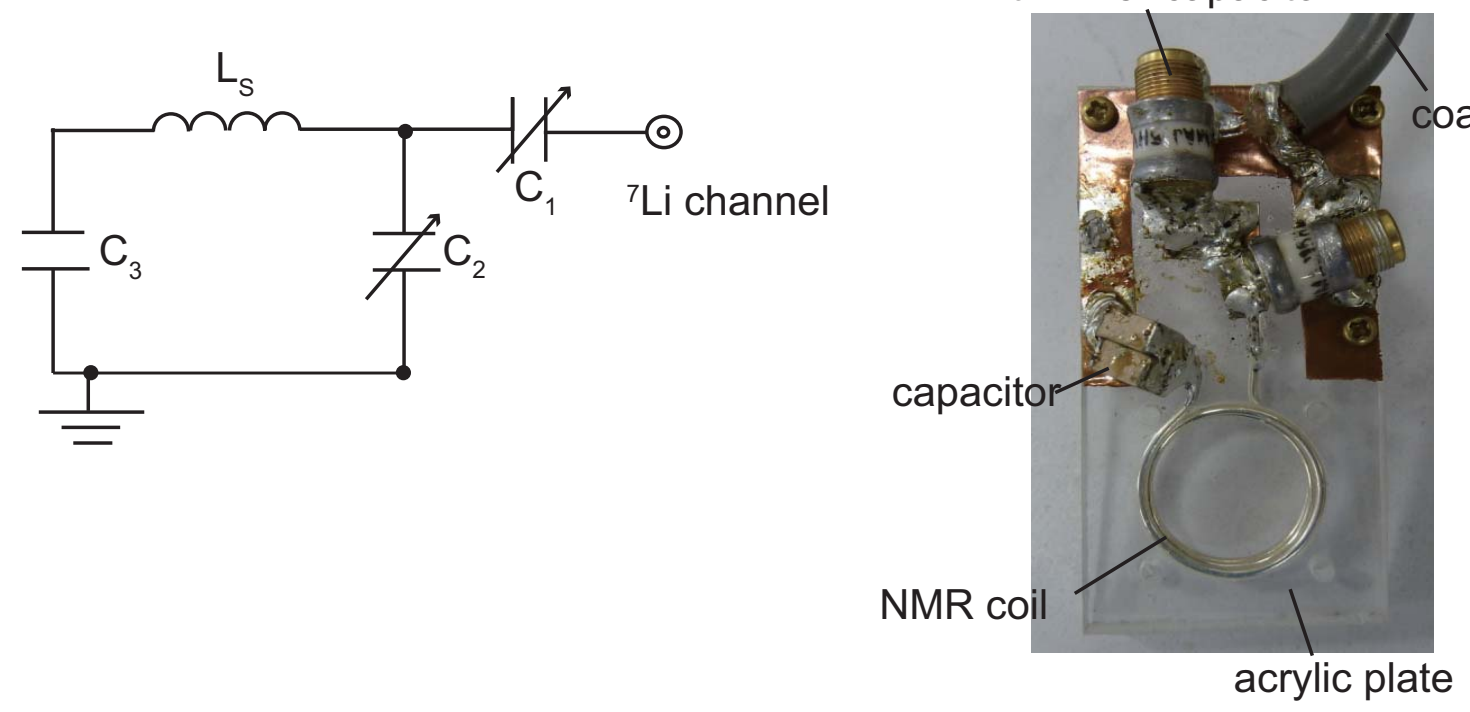

(c)

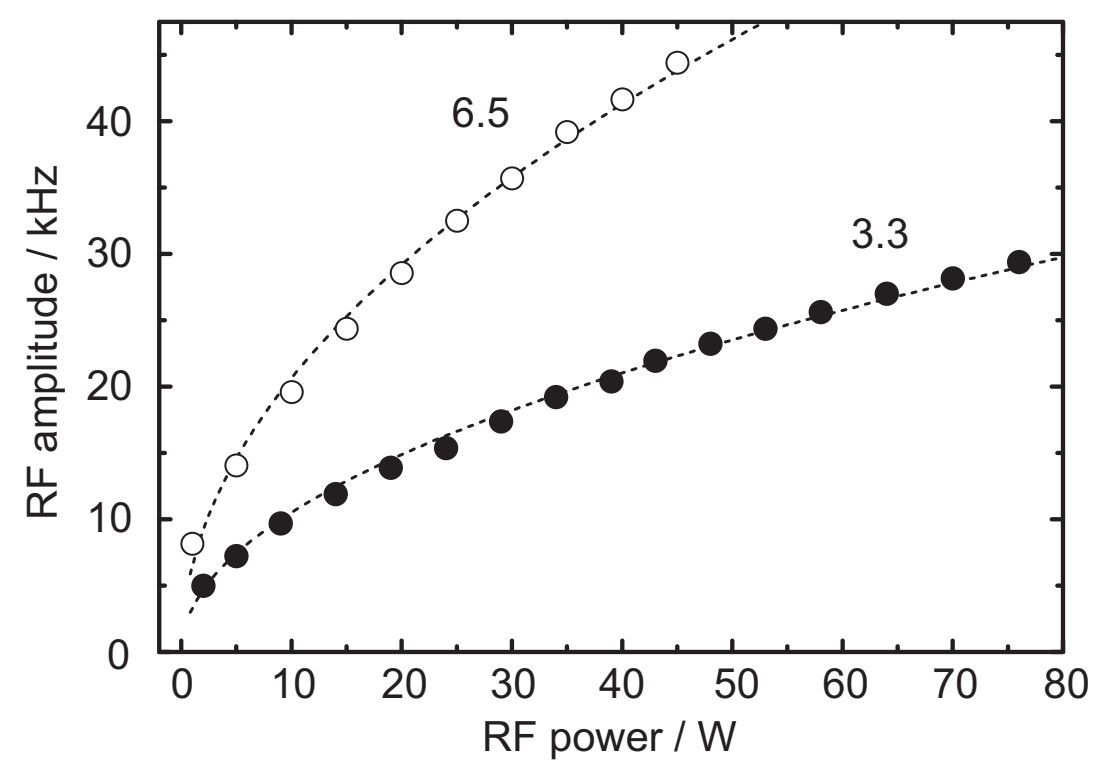

Fig. 2. 


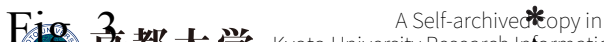

(3. 恋都大学 Kyyto University Research hingrmation Reposition hitps://repostory.kul k kyoto-uaci.jp

KURENAII

(c)

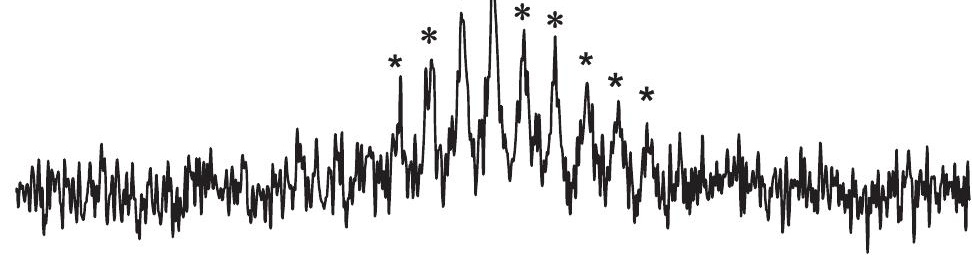

(b)

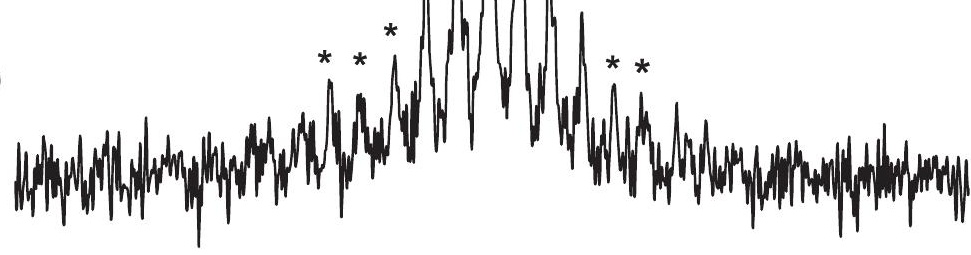

(a)

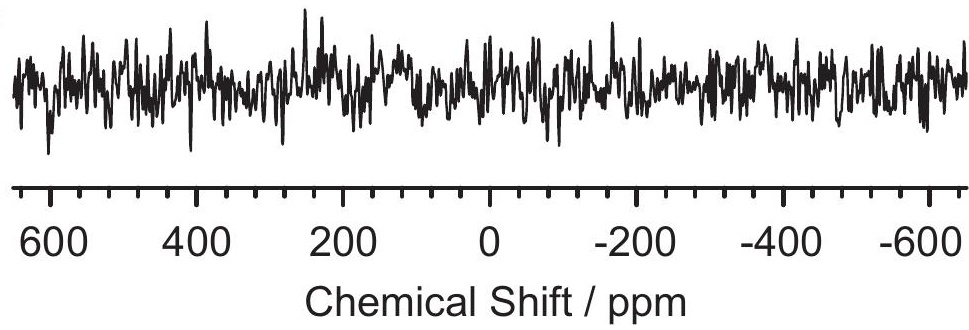




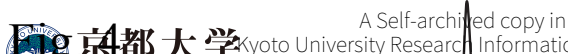

KYOTO UNIVERSITY

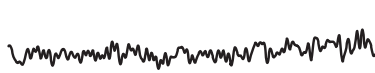

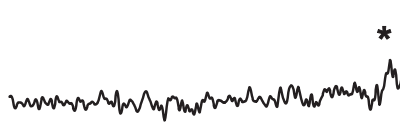

cumulmm.

$$
\text { * * * } 0 \text { min }
$$

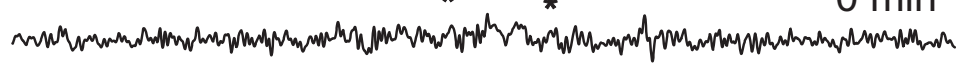

600 


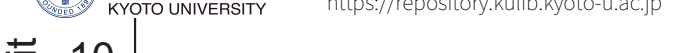

لَّ 10

Kyoto University Research Information Repository

$\frac{2}{\frac{\pi}{0}}$

8 .

$\bullet$

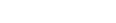

6

6

(2)

0

0

Fig. 5.

$t / \min$ 